\title{
Caráter e liberdade da vontade em Arthur Schopenhauer
}

\author{
Character and Freedom of the Will in Arthur Schopenhauer
}

\author{
Rodrigo Mota \\ Mestre em Filosofia pela Universidade Federal de Pernambuco (UFPE) \\ E-mail: rodrigomota@globo.com
}

\begin{abstract}
Resumo: Este artigo pretende expor a visão da filosofia de Arthur Schopenhauer sobre a possibilidade do livre-arbítrio humano, destacando o papel do caráter individual como fundamento último das escolhas pessoais. A onipresença da causalidade no nosso mundo representado nos impede de pensar algo sem razão suficiente. De onde vem nosso sentimento de liberdade e, principalmente, de responsabilidade? Veremos quais respostas Schopenhauer deu a estas e a outras questões relacionadas à liberdade da vontade.
\end{abstract}

Palavras-chave: Caráter; Livre-arbítrio; Vontade.

Abstract: This article intends to expose the vision of Arthur Schopenhauer's Philosophy on the possibility of human free will, focusing on the individual character as the ultimate foundation of personal choices. The omnipresence of causality in our represented world prevents us from thinking something without sufficient reason. From were, then, comes our feeling of freedom and, most importantly, of responsibility? We will see what answers Schopenhauer gave to those and other questions related to the Freedom of the Will.

Keywords: Character; Free will; Will.

La liberté est un mystère ${ }^{1}$

o ano de 1837, um senhor de meia-idade encontrou, enquanto lia a
Hallischen Literaturzeitung [Revista Literária de Halle], uma questão
apresentada pela Sociedade Real Norueguesa das Ciências de Drontheim tratando do problema da liberdade ${ }^{2}$. O autor da melhor resposta receberia um prêmio desta sociedade. Esse senhor era o então desconhecido filósofo alemão Arthur Schopenhauer e a questão era: "Pode-se demonstrar a liberdade da vontade humana a partir da autoconsciência?". O filósofo pôs-se a trabalhar, enviando seu opúsculo no final de 1838, recebendo o primeiro prêmio da Sociedade Real Norueguesa das Ciências de Drontheim em janeiro de 1839. O pensador desprezado ficou eufórico com o primeiro grande reconhecimento acadêmico e publicou em 1841, junto com outro ensaio sobre a moral (esse "não-premiado" pela Sociedade Real Dinamarquesa), uma obra intitulada "Die beiden Grundprobleme der Ethik" [Os dois problemas fundamentais da

1 "A liberdade é um mistério" teria afirmado o filósofo francês Nicolas Malebranche, segundo Schopenhauer (E/E, p. 139).

${ }^{2}$ SAFRANSKI, Rüdiger. Schopenhauer e os anos mais selvagens da filosofia. 
ética]. É importante observar que a questão pede especificamente que o problema do livre-arbítrio seja tratado no âmbito da autoconsciência e a definição desta última permeará grande parte do ensaio.

Para início de análise, Schopenhauer busca uma clara definição de liberdade. A idéia mais básica que nos vem à mente com esse conceito, de acordo com o filósofo alemão, é que ele é um conceito negativo. Negativo no sentido físico do termo, a liberdade é a ausência de impedimentos materiais de qualquer forma. Por isso dizemos de uma avenida sem carros que ela está livre, um preso depois de cumprir pena (ou fugir) está livre, uma imprensa sem censura é livre, quando estamos em um campo aberto estamos ao ar-livre etc. Pensamos os animais como livres, nesse primeiro sentido, pela sua capacidade de gerar movimento por sua própria vontade, quando não há nenhum tipo de impedimento. Estes obstáculos podem ser de vários tipos, mas sempre incidem sobre a vontade do agente e, para aqueles que pretendem ver um sentido positivo na liberdade, consideram livres tudo que apenas através da sua vontade se move ou por ela age. Portanto, segundo o pensamento de Schopenhauer, neste sentido mais básico de liberdade negativa como ausência de impedimento físico ou material para o cumprimento da ação ou movimento ordenado pela vontade, costuma considerar-se humanos e animais como seres livres. Esse significado físico do conceito de liberdade torna-se, inclusive, predicado dos animais, os diferenciando de outros seres pela capacidade de mover-se voluntariamente. Este sentido do termo é percebido de forma imediata e sem controvérsias sendo, portanto, o sentido mais comum do conceito de liberdade, estendendo-se até a chamada liberdade política. Consideramos uma nação livre aquela que não está sob o julgo de outra; um cidadão é politicamente livre quando não é impedido de participar do processo político do Estado ao qual pertence etc. Portanto, removendo qualquer possível determinação da vontade dos agentes envolvidos, podemos afirmar, nos baseando nas palavras de Schopenhauer, que uma ação voluntária é aquela contra a qual não há obstáculo físico ou material para a concretização desta ação, na qual se faz o que tem vontade de fazer. Num sentido puramente negativo de liberdade, esta é uma ação livre.

O segundo conceito de liberdade analisado por Schopenhauer é a chamada liberdade intelectual, o voluntário e o involuntário com respeito ao pensamento, como descrito por Aristóteles. Esse tipo de liberdade está próximo à liberdade física. Por isso passaremos desde já para a liberdade cuja existência a filosofia debate há séculos: a 
Revista Voluntas: Estudos sobre Schopenhauer - Vol. 6, № 1 - $1^{\circ}$ semestre de 2015 - ISSN: 2179-3786 - pp. 155-170.

liberdade moral, o chamado livre-arbítrio. Começamos a percebê-la quando notamos que nem sempre é necessário um impedimento físico para bloquear uma ação da vontade humana. Muitas vezes deixamos de fazer coisas em nosso próprio benefício sem necessariamente sermos materialmente constrangidos. Nesse caso, no lugar desses obstáculos físicos, motivos opostos aparecem como impedimento à ação, como, por exemplo, ameaças, promessas, perigos, etc. Da mesma forma como ocorre com a liberdade física, na liberdade moral, na ausência desses "contra motivos", a ação pode, em tese, proceder como desejada pelo agente. Um motivo pode ser ultrapassado por um contra-motivo mais forte. "Até mesmo o mais forte de todos os motivos, a preservação da própria vida, é sobrepujado por outros motivos: por exemplo, o suicídio e o sacrifício

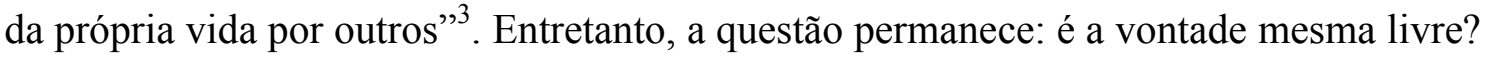
Até agora se tem pensado o livre-arbítrio pelo "poder" ao invés do "querer", nos diz Schopenhauer, deixando em aberto a questão da vontade livre. A própria noção comum de liberdade não toca na vontade, afinal livre é alguém que faz o que tem vontade, presumindo a liberdade no "ter vontade". No entanto, voltando nosso pensamento para a vontade, devemos questionar: queremos o que temos vontade? Uma solução à questão, questão essa que pressupõe um querer anterior, seria afirmar que sim e pensar em que queremos essa vontade, e queremos esse querer, assim por diante até encontrar um querer que não dependesse de nenhuma vontade. Mas se encontrássemos tal querer, poderíamos muito bem ter permanecido no primeiro, o que nos remete à pergunta: podese querer? A resposta a esta questão é o que tentamos descobrir desde o princípio. Essa questão, todavia, nos mostra como é impossível estabelecer uma ligação direta entre o conceito de liberdade, em seu sentido original empírico, e o conceito de querer, pois retornaríamos sempre às mesmas questões. Schopenhauer nos propõe abstrair o conceito de liberdade para podermos encontrar a ligação. Devemos, então, trabalhar com liberdade como a ausência de qualquer necessidade, mantendo assim o atributo negativo do conceito, como mostrado no início do ensaio. Iremos agora analisar o conceito positivo que dá sentido ao negativo: o conceito de necessidade.

O que é necessidade? A resposta mais comum é "necessário é aquilo, cujo

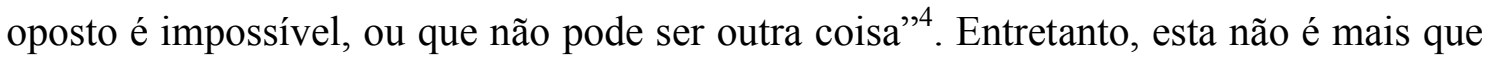
a explicação da palavra. O verdadeiro significado deve ser este, nas palavras de

\footnotetext{
${ }^{3}$ SCHOPENHAUER, A. E/E, Cap. I, p. 45-46.

${ }^{4}$ SCHOPENHAUER, A. E/E, Cap. I, p. 47. 
Schopenhauer: "necessário é aquilo que se segue de uma dada razão suficiente". Esta razão suficiente deve ser a causa lógica, matemática ou física de um efeito conseqüente, como, por exemplo, a conclusão de uma premissa, as leis da mecânica etc. Ou seja, sempre que esta dada causa, ou razão suficiente, esteja presente, sua conseqüência deverá seguir. Tudo aquilo que é consequência de uma determinada causa, percebemos como necessário na ocorrência desta causa. Tão clara é esta observação, para Schopenhauer, que os conceitos de consequência de uma dada razão suficiente e necessidade tornam-se conceitos intercambiáveis, um poderia perfeitamente ser colocado no lugar do outro. Seguindo essa lógica, portanto, ausência de necessidade significa ausência de uma razão suficiente. O oposto de necessário é o acidental. Na realidade, o acidental só o é relativamente, pois todo evento é necessário em relação à sua causa, mas em relação às outras causas simultâneas no espaço e no tempo, é acidental. A liberdade, então, como a ausência de toda necessidade, ou seja, independente de qualquer causa, pode ser definida como absolutamente acidental. Passando à ação humana, para esta ser livre de fato, teria, então, que ser livre de qualquer causa, qualquer necessidade. Pois se encontrarmos alguma razão suficiente para a ação, esta, como vimos, não pode ser considerada livre, mas determinada por alguma necessidade, na forma de causalidade. Daí, nos escreve Schopenhauer, vem a definição kantiana de liberdade como capacidade de iniciar por si mesmo uma série de mudanças. Este "por si mesmo" significando sem causa anterior. Esse tipo de liberdade já possui um termo técnico desde os escolásticos, que é “liberum arbitrium indifferentiae", um ato livre de qualquer influência anterior. Este ato violaria de alguma forma a determinação do princípio da razão suficiente, causalidade, que é, para o pensamento schopenhaueriano, a forma da nossa faculdade cognitiva. Essa capacidade extraordinária que possuiria o ser humano seria explicitada na situação em que de duas escolhas diametralmente opostas seriam igualmente possíveis. Antes de analisar esse fenômeno, Schopenhauer retorna à questão originalmente proposta pela Sociedade Real Norueguesa das Ciências de Drontheim e busca definir o que é a referida autoconsciência e sua relação com o tema liberdade.

Como usualmente, Schopenhauer inicia sua análise com a mais básica das definições: autoconsciência é a consciência do próprio eu, em oposição à consciência das outras coisas, esta última sendo o que se considera a faculdade cognitiva. Esta

\footnotetext{
${ }^{5}$ SCHOPENHAUER, A. E/E, Cap. I, p. 47. 
Revista Voluntas: Estudos sobre Schopenhauer - Vol. 6, № 1 - $1^{\circ}$ semestre de 2015 - ISSN: 2179-3786 - pp. 155-170.

faculdade de perceber as coisas como objetos é determinada pelas formas do entendimento: tempo, espaço e causalidade. Estas formas estão em nós, não como autoconsciência, mas na consciência das outras coisas, o conhecimento objetivo. Outro sentido de consciência, que será tratado no devido tempo, é a consciência no sentido moral, a nossa responsabilização pelas nossas ações. Na prática, sabemos que nossa consciência é, na maior parte das vezes, dirigida para fora, dirigida às coisas como objetos do nosso conhecimento, ou seja, usamos muito mais a nossa faculdade cognitiva do que a chamada autoconsciência. Essa consciência do mundo real, dirigida para fora de nós, capta a realidade perceptivamente, a generaliza em conceitos, e a combinação destes conceitos constitui basicamente nosso pensar. Somente ao subtrairmos isso, a maior parte da nossa consciência, é que obtemos o que chamamos "autoconsciência". Como "órgão" da autoconsciência possuímos também, numa imagem metafórica, um sentido interno, já observado por grandes pensadores, como Santo Agostinho. Metafórica porque, nos esclarece Schopenhauer, a autoconsciência é imediata. E como o ser humano percebe seu próprio Eu imediatamente? Como um ser querente. Quando olhamos dentro de nós mesmos, nos diz Schopenhauer, o que vemos são volições. Volições nos seus mais variados graus: desejos, aspirações, frustrações, tristeza, alegria, medo etc. Sejam quais forem esses movimentos da vontade, tanto atrativos quanto repulsivos, eles são os únicos objetos da autoconsciência. Essas volições são voltadas para o mundo exterior, o reino da consciência das outras coisas, e daí tiram seus objetos. Mas a questão principal para nós é em que medida esses objetos exteriores determinam a direção da nossa vontade.

$\mathrm{O}$ ato de vontade [Willensakt] (chamo assim para, por enquanto, não associarmos o significado mais comum de "ato voluntário" como sinônimo de "ato livre") é dirigido a algum objeto, isto é claro. Este ato também só pode ser pensado em relação a esse objeto, não existe uma vontade fora de um contexto objetivo. Como vimos anteriormente, a questão que surge é se essa vontade, objeto único da nossa autoconsciência, pode ser considerada livre por si só ou é determinada por algo externo? Schopenhauer nos fornece a seguinte resposta:

o ato de vontade, que é inicialmente apenas objeto da autoconsciência, vem à tona como o resultado de algo que pertence à consciência de outras coisas e, portanto, é objeto da faculdade cognitiva, objeto este que, nessa relação, chamar-se-á motivo e constituir-se-á o conteúdo da volição, ao qual esta é dirigida, ou seja, ela pretende modificar o 
objeto e, portanto, reage a este: desta reação consiste toda sua essência ${ }^{6}$.

Portanto, sem esse objeto exterior, o ato de vontade perderia sua própria natureza e não poderia existir. $E$, falando em necessidade, a pergunta que Schopenhauer nos faz é se, na aparição desses objetos, a volição deve necessariamente aparecer, da mesma forma que quando algo se inflama, o calor deve necessariamente acompanhar. Se, por acaso, uma determinada causa falha no seu intento, é porque a intensidade da sua motivação não foi alta o suficiente. Para Schopenhauer, "quem não é seduzido por 10 Ducados, mas titubeia, o será por 100"7. Para o filósofo alemão, ademais, a nossa autoconsciência, por sua simplicidade de conteúdo, não nos pode fornecer a resposta se os motivos são necessários para a volição, ou sobre causalidade em geral, já que a própria noção de necessidade está localizada no entendimento, que é voltado para os objetos exteriores. Quando olhamos para dentro de nós, quando questionamos a chamada autoconsciência, o máximo de resposta que encontramos é: eu posso querer; se quero agir, posso ordenar meu corpo e ele poderá agir de acordo, só me basta querer; resumindo “ 'eu posso fazer aquilo que quero'. Para além disso não vai, o depoimento da nossa autoconsciência imediata" ${ }^{\text {. }}$. Assim retornamos à definição do senso-comum do conceito de liberdade: poder fazer o que se quer. Liberdade seria a ação de acordo com a vontade. É essa a idéia de liberdade que nos fornece a autoconsciência. O que devemos buscar, nos diz Schopenhauer, é a relação entre a vontade e o motivo, quem determina quem.

Não podemos, para Schopenhauer, ter vontade de duas coisas distintas. Ao fazermos uma "escolha" entre dois desejos, o vencedor era, desde sempre, nossa vontade. O ser humano comum "confunde, a saber, desejos com vontades. Desejos pode ele opor; mas tem vontade apenas de um: e qual desses será, apenas se manifestará, até para a autoconsciência, na ação"". Só podemos saber se o que sentimos é desejo ou vontade a posteriori, após nossa própria ação o mostrar. A ilusão da hipótese de duas iguais possibilidades para duas escolhas opostas vem dessa resposta padrão nos fornecida pela autoconsciência: "eu posso fazer o que tenho vontade", mas, na prática, o que essa frase nos mostra é que "se eu o quiser, posso fazê-lo", ou seja, "se minha

\footnotetext{
${ }^{6}$ SCHOPENHAUER, A. E/E, Cap. II, p. 53.

${ }^{7}$ SCHOPENHAUER, A. E/E, Cap. II, p. 54.

${ }^{8}$ SCHOPENHAUER, A. E/E, Cap. II, p. 55.

${ }^{9}$ SCHOPENHAUER, A. E/E, Cap. II, p. 56. 
vontade se inclinar para o $x$, poderei querê-lo e, consequentemente, fazê-lo; se se inclinar para $y$, o mesmo", no fim das contas quem decide é a vontade. Como seu objeto se situa na consciência das outras coisas, a autoconsciência não o capta. Nossa vontade vista de dentro, através da autoconsciência, só enxerga a si própria, alheia aos objetos que a fundamentam, e nos dá a falsa impressão de liberdade de escolha. Nossa vontade, vista de fora, pela consciência das outras coisas, faculdade cognitiva, percebe tanto os objetos dessa vontade quanto a nós próprios como objetos. Schopenhauer resume este pensamento da seguinte forma:

Portanto, esse sentimento localizado na autoconsciência, 'eu posso fazer o que eu quero', sempre nos acompanha, mas significa somente que as decisões, ou atos definitivos da nossa vontade, apesar de se originarem nas profundezas obscuras do nosso interior, sempre se manifestarão no mundo visível de imediato, já que a este mundo também pertence, como todas as coisas, o nosso corpo. Essa consciência constrói a ponte entre o mundo interior e o mundo exterior, os quais de outra forma ficariam separados por um abismo sem fundo ${ }^{10}$.

Esse dualismo interior-exterior é a chave para entendermos tanto o que é a liberdade, se ela existe e o porque das distintas respostas dadas por brilhantes filósofos por séculos. Para Schopenhauer devemos olhar desde fora. Compreender isto é de uma importância imensurável, pois toca a essência mesma do ser humano. Percebemos, baseado no acima descrito, que a vontade está no âmago dessa essência, tanto que nos surge na autoconsciência como nosso próprio "eu”, de forma que o ser humano "é como quer, e quer como ele é. Conseqüentemente, perguntar se ele pode querer de outra forma, além da que tem vontade, é perguntar se ele pode ser outro, além de si próprio" ". Dessa forma, a questão levantada pela Sociedade Real Norueguesa das Ciências de Drontheim está respondida negativamente. Nossa autoconsciência não pode nos provar que nossas ações são livres porque, percebendo apenas o próprio querer, essa questão está fora das suas próprias possibilidades. A autoconsciência nos diz que podemos fazer o que queremos, mas não por que queremos isto e não aquilo, ou se diante de duas escolhas, temos igual possibilidade de "querer" tanto uma quanto outra. O verdadeiro lugar para essas questões está na nossa percepção exterior, no nosso entendimento avaliado pela nossa razão, e o que essas faculdades cognitivas nos dizem

\footnotetext{
${ }^{10}$ SCHOPENHAUER, A. E/E, Cap. II, p. 57.

${ }^{11}$ SCHOPENHAUER, A. E/E, Cap. II, p. 60. 
é que a vontade humana, em um determinado momento com um determinado caráter, só pode querer de uma única maneira. Portanto, o agir humano, visto pelo intelecto, é tão determinado pela causalidade, nesse caso expressa em motivos, quanto todo o resto da natureza.

Um ponto fundamental a ser notado na vontade humana é que ela se manifesta de uma forma singular em cada indivíduo. Essa forma faz com que os mesmos motivos provoquem reações distintas em cada ser humano. Essa natureza individual e particular da vontade corresponde ao que conhecemos por caráter. Mais especificamente o caráter empírico, conhecido na experiência. É esse caráter que determina o efeito que vários motivos terão em uma determinada pessoa. Esse caráter particular traz consigo todos os efeitos possíveis que as motivações deverão trazer, da mesma forma que as propriedades ou qualidades determinam, nos minerais e plantas, os efeitos das causas no sentido estrito e os estímulos, respectivamente. Além disso, "como as forças naturais ele [o caráter] é também original, imutável e inexplicável. Nos animais é diferente em cada espécie, nos seres humanos, em cada indivíduo"12. Apesar de nos animais mais inteligentes notarmos certa distinção individual de caráter, ainda nestes o caráter da espécie predomina sobre o do indivíduo. Apenas nos seres humanos o caráter tem, de fato, expressões individuais claras, tanto que entre uma pessoa e outra pode haver diferenças tão gritantes de comportamento que quase pensamos possuírem naturezas distintas. É, portanto, esse caráter humano que, seguindo a orientação de Schopenhauer, iremos estudar para entendermos a manifestação da causalidade chamada motivação e a sua relação com a liberdade da vontade humana.

Primeiramente, observaremos essa primeira característica do caráter humano: ele é individual, isto é, é distinto em cada pessoa. Características fundamentais que se repetem de um indivíduo a outro proveem, naturalmente, da espécie. Entretanto, observamos diferenças gritantes, por exemplo, intelectuais e morais, de um indivíduo a outro. É por fatores como estes que os motivos operam de maneira distinta de uma pessoa a outra. Portanto, nos diz Schopenhauer "do conhecimento dos motivos sozinhos não se pode predizer o ato, mas, além disso, precisa-se conhecer, com exatidão, o caráter" ${ }^{, 13}$.

A segunda importante propriedade do caráter humano é que ele é empírico, o que quer dizer que apenas o podemos conhecer, tanto o nosso próprio como o de 
Revista Voluntas: Estudos sobre Schopenhauer - Vol. 6, № 1 - $1^{\circ}$ semestre de 2015 - ISSN: 2179-3786 - pp. 155-170.

outrem, através da experiência. Portanto, mesmo nós não temos total certeza de como agiremos perante determinada motivação até que esta se apresente. Por isso nos surpreendemos até mesmo com nossa postura perante determinadas situações. Esta imprevisibilidade das ações humanas contribui, segundo Schopenhauer, para a ilusão do livre-arbítrio humano. É através do conhecimento empírico das reações da vontade do indivíduo a determinados motivos que vemos os contornos do seu caráter. Com isso nos aproximamos de um fenômeno vital para a própria existência da sociedade humana: a confiança. De acordo com Schopenhauer, "em geral, tratamos uma pessoa que conhecemos bem como qualquer outro objeto cujas propriedades já nos são familiar e sabemos de antemão o que podemos esperar dela e o que não" ${ }^{14}$. A confiança surge justamente porque não podemos ter um conhecimento total sobre o caráter de uma pessoa (como vimos, esse conhecimento nos é apenas dado a posteriori, na experiência), e, portanto, necessitamos de um elemento, quase um salto de fé, que nos faça agir com essa pessoa. O filósofo e sociólogo alemão Georg Simmel, tratando do tema em sua obra Soziologie, de 1908, coloca a confiança como "a hipótese da conduta futura, que é segura o suficiente para fundamentar a ação prática" 15 e como a "hipótese de uma situação intermediária entre saber e não-saber em torno dos seres humanos. Aquele que conhece completamente não precisa confiar, aquele que não conhece nada não pode racionalmente confiar" ${ }^{\prime 16}$. Schopenhauer, ademais, observa até mesmo o fenômeno da autoconfiança como prova da sua tese. Dependendo de como agimos em circunstancias semelhantes no passado, teremos maior ou menor segurança do sucesso de uma determinada ação no presente ou futuro. A pessoa que observa bem suas próprias ações, seus impulsos e tendências, negativas e positivas, pode saber o que esperar e o que não esperar de si mesmo, pode agir artisticamente onde antes agia pela natureza, com graça e firmeza, sendo fiel ao seu caráter.

O terceiro aspecto do caráter humano é a sua constância. Para Schopenhauer, nosso caráter é imutável, permanece o mesmo por toda nossa vida. É uma afirmação polêmica, com graves implicações morais que serão posteriormente trabalhadas. Para o filósofo alemão, por traz das mudanças dos anos, dos relacionamentos, aprendizados etc, existe o sempre idêntico $\mathrm{Eu}$ real. Os seres humanos, portanto, no fundo nunca mudam; e se fosse possível serem criadas as mesmas circunstâncias de uma

\footnotetext{
${ }^{14}$ SCHOPENHAUER, A. E/E, Cap. III, p. 88.

${ }^{15}$ SIMMEL, Georg. Soziologie: Untersuchungen über die Formen der Vergesellschaftung, p. 393.

${ }^{16}$ SIMMEL, Georg. Soziologie: Untersuchungen über die Formen der Vergesellschaftung, p. 393. 
determinada ação passada, agiríamos da exata mesma forma como agimos então. Schopenhauer utiliza novamente o exemplo da confiança como prova. Para ele, o fato de não confiarmos em alguém que sabemos ter agido de forma desonesta no passado mostra que, na prática, temos quase que instintivamente a certeza da imutabilidade do caráter $^{17}$. A estigma que fere, pelo resto da vida, a honra de alguém que cometeu às vezes apenas uma falta grave, reforça essa ideia. Outro exemplo da imutabilidade do caráter é o do peso na consciência que carregamos por algum malfeito realizado há anos. De acordo com Schopenhauer, isso ocorre porque assumimos que o caráter permaneceu o mesmo desde então. Entretanto, afirma ainda o autor, em relação a, digamos, delitos menores de nossa juventude, não os carregamos com tanto peso, pois os vemos como fundamentados na ignorância da época, quando não sabíamos as reais conseqüências das nossas ações, e, portanto, não conhecíamos contra-motivações suficientes para nos impedir de agir de tal maneira. Este último ponto é essencial para entendermos as conseqüências morais de reconhecermos nossa consciência como inata e imutável. Segundo Schopenhauer, o poder da determinação do nosso caráter em nossas ações é tão grande que ocorrem casos nos quais, por mais que a pessoa se esforce para mudar seu comportamento, com plena consciência que este é mau, se vê praticando o mesmo deslize quando o motivo o chama. A única coisa que pode ser corrigida no comportamento de alguém é o conhecimento. Como mencionamos acima, um melhor conhecimento dos motivos e suas consequências pode fazer-nos enxergar motivações mais fortes do que aquela do momento. Dessa forma refletimos e agimos, não livremente rejeitando aquela atitude ruim, mas em busca de outra que nos favoreça mais. Schopenhauer observa que essa é a base do sistema penal norte-americano de sua época, elogiado por ele, que não pretende mudar o caráter das pessoas, mas cria dificuldades para elas atingirem suas metas pelo caminho da desonestidade, do mal ao outro, e mostra-lhes que o outro caminho, o da retidão, da honestidade etc, irá favorecer-lhes mais. Essas mudanças ocorrem apenas na nossa cognição, não no caráter. Entretanto, como o motivo é a causalidade passando pela cognição, esta lhe fornece novas informações, isto é, novas motivações para agir, que não aquelas dadas naquele

17 Particularmente acredito que se trate mais de prudência do que certeza. Da mesma forma, nas discussões sobre a natureza humana, as quais têm sérias conseqüências políticas, acredito que, na dúvida, é mais seguro agirmos como se o homem, sem rédeas morais, legais e instituições coercitivas, fosse o lobo do homem. Isso não quer dizer que não devemos acreditar que existam seres humanos incapazes por natureza de fazer mal a outros. Sobre isso, ver o outro opúsculo de Arthur Schopenhauer que compõe, junto com o que trabalhamos no momento, o livro "Die Beiden Grundplobleme der Ethik": "Über die Grundlagen der Moral". 
instante. Esta capacidade da cognição de expansão e correção é a função e meta de toda educação. O aprendizado surge aí para nos dar um alívio moral mesmo com a dura afirmação que nosso caráter não pode mudar. Nas palavras de Schopenhauer:

O desenvolvimento da razão através de informação e insights de todos os tipos é moralmente importante, pois fornece à pessoa acesso a motivos que de outra forma ficariam inacessíveis. Enquanto não os podia compreender, eles não estavam presentes à sua vontade. Portanto, sob as mesmas circunstâncias externas a situação de uma pessoa pode ser bastante distinta na segunda vez do que o foi na primeira, contanto que ela tenha podido, neste meio tempo, compreender aquelas circunstâncias corretamente e completamente, tanto que motivos os quais para ela eram antes inacessíveis, agirão sobre ele agora. [...] Entretanto, nenhuma influência moral pode atingir mais longe do que a correção da cognição e a tentativa de remoção das falhas de caráter de uma pessoa por meio de conversas e moralização e, portanto, reformar seu caráter mesmo, sua moralidade essencial, é exatamente como tentar transformar, por forças externas, chumbo em ouro ${ }^{18}$.

A quarta e última característica fundamental do caráter humano é este ser inato. Não é uma obra de arte ou acidente, mas fruto da própria natureza. Como prova disto, Schopenhauer menciona o fato de percebermos já nas crianças, em pequena escala, o adulto que está por vir, além da evidência observada quando duas crianças criadas sob praticamente as mesmas condições, tornam-se adultos bastante distintos. O filósofo alemão, provavelmente baseando-se em sua própria experiência familiar ${ }^{19}$, acredita encontrar características hereditárias no caráter das crianças, mas apenas pelo lado paterno. Já o lado materno forneceria as características intelectuais da prole. Daí se segue que as virtudes e os vícios são também inatos. Esse ponto é importante na nossa discussão, pois mostra que, para Schopenhauer, esses impulsos para o bem ou para o mal que temos em nós são as únicas partes que compõem nosso caráter. Alguém que, depois de agir desonestamente age de outra forma em uma semelhante situação posterior não é muito distinto de um farsante, pois o fez apenas porque um motivo mais forte contrário surgiu. Ou seja, no conceito de caráter schopenhaueriano, o aprendizado e a memória são apenas acidentes. Para ele, pensar diferente disso seria considerar cada caráter como uma tabula rasa lockeana e não explicaria como duas pessoas com a

${ }^{18}$ SCHOPENHAUER, A. E/E, Cap. III, p. 91.

${ }^{19} \mathrm{O}$ pai de Arthur Schopenhauer, Heinrich Floris Schopenhauer, era um disciplinado, altivo e honrado homem de negócios, enquanto sua mãe, Johanna Schopenhauer, após a morte do marido, se revelou uma talentosa escritora, fazendo parte do seleto grupo em torno de Johann Wolfgang von Goethe em Weimar (SAFRANSKI, Rüdiger. Schopenhauer e os anos mais selvagens da filosofia). 
mesma criação podem tomar caminhos totalmente diferentes. Mas será mesmo possível duas pessoas com a "mesma" criação? Na visão de Schopenhauer, esse questionamento só poderia ser respondido fora da sua tese se considerássemos que cada indivíduo, com seu caráter em branco, tivesse uma interpretação individual dos objetos, o que levaria à posterior diferenciação. Ainda assim, será que a única alternativa à sua explicação é a da tabula rasa? Será que o caráter não pode incluir mais do que o que se nos apresenta ao nascermos?

Schopenhauer argumenta, em defesa da sua tese da congenitabilidade do caráter, que, se este nascesse em branco, igual em todos, não notaríamos suas manifestações nas crianças e estas poderiam até morrer sem um caráter adquirido, o que para ele é absurdo. Outro argumento importante a favor desta tese é que se de fato nosso caráter fosse totalmente determinado pelo ambiente, então nossa responsabilidade moral não existiria. Se somos maus porque o acaso nos fez assim, ou porque fomos criados em um ambiente com pessoas más, onde fica a nossa responsabilidade? Schopenhauer nos mostra que nossa própria consciência desmente essa hipótese, quando lamentamos ter agido de uma determinada forma em determinada circunstância.

O caráter inato e imutável humano torna-se o pressuposto da motivação como causalidade, da mesma forma que nas criaturas inanimadas, os efeitos se manifestam por dois fatores, a saber, a força geral e natural que se manifesta nesse instante e a causa particular que suscita essa manifestação. Nos seres humanos estes fatores são, respectivamente, o caráter e o motivo. "Dados ambos, o efeito segue inevitavelmente. Para uma ação diferente ocorrer, ou um motivo diferente ou um caráter diferente teria de ser posto" ${ }^{20}$. Entretanto, vale a pena novamente ressaltar que isso não quer dizer que as ações humanas possam ser matematicamente preditas, mesmo numa tese determinista como a de Schopenhauer, pois, como já colocamos, o caráter teria de ser conhecido $a$ priori, como se o lêssemos num manual, o que é impossível, sendo, como o próprio filósofo alemão nos explicou, as ações que expõem esse caráter conhecidas apenas $a$ posteriori, além das constantes e complexas modificações da nossa mente, que, em constante aprendizado, alteram e "maquiam" constantemente a forma de interpretarmos esses mesmos motivos. Schopenhauer resume da seguinte forma sua doutrina do caráter individual:

${ }^{20}$ SCHOPENHAUER, A. E/E, Cap. III, p. 95. 
O caráter inato de uma pessoa determina no essencial até as metas pelas quais ela se esforça: os meios que ela toma para este propósito são determinados em parte pelas circunstâncias externas e em parte pelas suas concepções destas, cuja veracidade depende, por outro lado, do seu entendimento e educação. Suas ações particulares ocorrem como produto final de tudo isso, assim como todo o papel que ela representa no mundo ${ }^{21}$.

Fazendo novamente uma analogia com as ciências naturais, particularmente a química, Schopenhauer lembra uma fórmula escolástica chamada operari sequitur esse, cujo princípio atesta que cada substância reagirá de acordo com sua natureza. No caso da química testando-as a partir de reagentes, no caso humano tentando-o com diferentes motivações. De todas as formas, o que Schopenhauer nos quer provar com essa analogia é que, da mesma forma que cada substância expõe sua essência na reação à fatores externos, nós humanos expomos nosso caráter em nossas ações, estimuladas por motivos, não podendo agir contra este caráter, ou seja, contra a nossa própria natureza. O filósofo alemão também recorre a um argumento ontológico, afirmando não ser possível uma existência sem essência. Toda coisa em existência deve ser algo, portanto, deve possuir uma natureza definida, algo que defina suas propriedades e as suas formas de ação no mundo, por cuja virtude se é o que é. O ser humano não poderia ser diferente. Também nós possuímos essa essência que nos faz sermos nós e não outra coisa. Por isso, nos diz o pensador, supor que agimos de uma maneira em um momento e de outra completamente diferente em outro momento, dada as mesmas condições e sob a ação da mesma causa, ainda que de forma abstrata, é negar essa essência mesma. Seria como esperar que a cerejeira que nos forneceu belas cerejas esse ano, nos dê pêras no próximo. "O livre-arbítrio significa, analisado com cuidado, uma Existentia sem Essentia; que significa que algo é e ao mesmo tempo é nada, o que por sua vez significa não é, portanto, é uma contradição"22.

Nada melhor para coroar uma teoria filosófica do que ligá-la às maiores mentes que a humanidade já produziu. Com Arthur Schopenhauer não poderia ser diferente. Além das fundamentações teóricas e empíricas já mostrada, ele reveste sua tese com a sabedoria dos antigos. O insight que leva a essa conclusão, a saber, que o ser humano não é independente da lei da causalidade e, portanto, não é livre no sentido absoluto, está presente em alguns dos pensadores de maior grandeza, independente das suas

\footnotetext{
${ }^{21}$ SCHOPENHAUER, A. E/E, Cap. III, p. 95-96.

${ }^{22}$ SCHOPENHAUER, A. E/E, Cap. III, p. 97. 
eventuais divergências. $\mathrm{O}$ maior exemplo da antiguidade e prestígio dessa idéia é o paradoxo difundido, acredita-se ${ }^{23}$, pelo filósofo francês Jean Buridan no século XIV. O paradoxo afirma que, se supormos um asno com igual intensidade de fome e sede, em igual distancia entre um balde d'água e uma porção de feno, morrerá de sede e fome, pois não terá critério para tomar a decisão de qual necessidade suprir primeiro. $\mathrm{Na}$ verdade, nos esclarece Schopenhauer, esse paradoxo é muito mais antigo que Buridan, aparecendo em Dante Alighieri um século antes e, na mais provável fonte de todos os exemplos posteriores desse sofisma, em Aristóteles, na sua obra De Caelo, da seguinte forma: "do homem que, apesar de excessivamente faminto e sedento, e ambos de forma igualitária, estando equidistante da comida e da água, é, no entanto, condenado a ficar onde está" ${ }^{24}$. Segundo Schopenhauer, a questão da liberdade da vontade humana é uma espécie de definidora de uma mente distinta (naturalmente, aqueles que pensam como ele são as grandes mentes, enquanto o restante segue o entendimento das massas, de que o livre-arbítrio indiferente existe), excetuado "meios-termos" como Gottfried Leibniz, quem ele considera muito mais um matemático erudito que filósofo.

Para o autor de "O mundo como vontade e representação", um pensador honesto e preparado deve poder responder a essas duas questões quando tratar da liberdade da vontade humana: 1) Se a um ser humano em determinada circunstância são possíveis duas ações ou apenas uma; 2) Se, considerando que o caráter de uma pessoa é imutável e o mundo fenomênico é determinado necessariamente pela causalidade, da qual nada pode fugir, pois seria algo sem causa, sem razão suficiente, poderia o curso da vida desta pessoa ter sido de alguma outra forma daquela que foi? A resposta de um verdadeiro filósofo, no julgamento de Schopenhauer, é: apenas uma ação é possível e, portanto, todas as ações de um ser humano se passam de uma única forma, a única forma possível, em todos os aspectos; em outras palavras: "tudo o que acontece, do maior ao menor, acontece necessariamente. Quidquid fit necessario fit ${ }^{\prime 25}$. Isso significa que nossos atos não são nem poderiam ser, como se deve crer se se acredita no livrearbítrio indiferente, um novo início da série de causalidade. Nada há de novo sob o sol, como afirmou o Eclesiastes há séculos. Entretanto, nossas ações trazem sim algo, não novo, mas oculto: a revelação de quem somos nós. É após o ato cometido que

\footnotetext{
${ }^{23}$ O paradoxo leva seu nome - "O asno de Buridan" - apesar de não haver sido encontrada referência a este em suas obras, como atesta o próprio Schopenhauer (E/E) que alegava possuir uma antiga edição da obra Sophismata, sem a famosa ilustração que mostraria o perplexo eqüídeo.

${ }^{24}$ ARISTOTLE. On the Heavens, p. $486\left[295_{b} 1,31-33\right]$.

${ }^{25}$ SCHOPENHAUER, A. E/E, Cap. III, p. 99. 
Revista Voluntas: Estudos sobre Schopenhauer - Vol. 6, № 1 - $1^{\circ}$ semestre de 2015 - ISSN: 2179-3786 - pp. 155-170.

enxergamos a natureza de quem cometeu, mesmo que sejamos nós próprios. Schopenhauer atribui a essa verdade as antigas crenças no tirânico poder do destino, ao fatalismo dos maometanos e até na doutrina da eleição pela graça dos cristãos. É então que o filósofo alemão nos surpreende incluindo entre as evidências dessa verdade a existência da premonição, em sonhos etc, que pressupõe um futuro já predeterminado. Para ele, é inconteste a evidência de tais fenômenos paranormais, corroborando sua tese. Segundo ele, devemos considerar os eventos no mundo como as palavras de um livro, sabendo que estão lá mesmo antes de as lermos.

Reconhecendo a ausência da liberdade absoluta, Schopenhauer adianta-se à principal questão que vem à mente após refletirmos as possíveis conseqüências práticas de tal descoberta: onde fica, então, a liberdade moral? O agudo pensador reconhece que possuímos dentro de nós um senso de responsabilidade por nossas ações que talvez somente alguém com transtornos mentais poderia negar. Schopenhauer afirma que este senso de responsabilidade cai sobre o nosso caráter: É por ele que nos sentimos responsáveis. Até mesmo o julgamento das outras pessoas sobre nossas ações também sai do objeto, a ação, em direção ao sujeito. O sentimento de culpa revela a existência da responsabilidade, que exige liberdade moral, a qual, de acordo com a filosofia de Schopenhauer, se localiza no caráter humano. Nossas ações pressupõem, em igual medida, a presença do caráter e a ocorrência do motivo para se realizarem. O caráter é a natureza empírica e imutável de uma vontade individual. Sendo o caráter, nessa ação, tão necessário quanto o motivo, sentimos que o ato procede de nós, como o "eu quero", que vimos no início deste trabalho e que criava a ilusão da liberdade absoluta. É esse sentimento da procedência subjetiva do ato que se chama responsabilidade moral. A chamada "consciência" é o progressivo e íntimo conhecimento da natureza da nossa vontade, que determina nossas escolhas, entretanto, apenas ex post facto. Apenas temos essa consciência reflexiva antes dos atos quando estes se assemelham a outros passados, os quais temos então referência de como agimos e como deveríamos agir. Vimos que, segundo Schopenhauer, não existe liberdade absoluta na ação humana. Então, como ele coloca a liberdade moral no caráter? Como pode coexistir a estreita necessidade com nossa responsabilidade? A explicação que nos oferece é a do seu mestre póstumo Immanuel Kant. Para Kant, o mundo fenomênico, submetido às formas puras da intuição sensível, não é a coisa-em-si, mas a aparência desta dentro destes limites do 
conhecimento humano ${ }^{26}$. O mundo dos fenômenos está, portanto, submetido a essa estrita lei da causalidade, mas a coisa-em-si, que está fora do tempo-espaço-causalidade, não está. O caráter empírico, que é aquele do qual podemos ter algum conhecimento, está, conseqüentemente, submetido a essas leis. Não estando submetido a essas leis, o númeno, conceito negativo para designar o que nos é vedado conhecer, é o campo onde se localiza a vontade como liberdade absoluta, pressupondo a existência, na coisa-em-si, de um caráter ininteligível. Essa liberdade transcendental não aparece, não é fenômeno, não pode nos ser conhecida. Está fora do tempo, é o ser interior do homem-em-si. É por conta dessa misteriosa liberdade transcendental que os seres humanos são autores dos seus atos. O caráter empírico é apenas a aparência desse caráter inteligível, que é a vontade livre apenas $e m$-si, fora do campo das aparências. Essa liberdade não opera nas ações individuais, mas na existência e essência mesma do humano. Faz-se necessariamente o que se tem vontade, pois já se é o que se quer. Do que se é vem a necessidade do agir.

\section{Referências bibliográficas}

ARISTOTLE. On the Heavens. In: The complete Works of Aristotle: The revised Oxford translation, Vol. I. Princeton: Princeton University Press, 1995.

KANT, Immanuel. Crítica da Razão Pura. $7^{\mathrm{a}}$ ed. Lisboa: Fundação Calouste Gulbenkian, 2010.

SAFRANSKI, Rüdiger. Schopenhauer e os anos mais selvagens da filosofia. $1^{\mathrm{a}}$. Edição. São Paulo: Geração Editorial, 2011.

SCHOPENHAUER, Arthur. Über die Freiheit des menschlichen Willens; Über die Grundlage der Moral. Zürich: Diogenes Verlag AG., 1977. E/E.

SIMMEL, Georg. Soziologie: Untersuchungen über die Formen der Vergesellschaftung. Frankfurt am Main: Suhrkamp, 1992. 